\title{
Modelling of Hearing Aid's Digital Signal Processor
}

\author{
Suad Abdulkareem *, Isam Janajreh ${ }^{a}$ \\ ${ }^{a}$ Khalifa University, Abu Dhabi, UAE
}

\begin{abstract}
According to the World Health Organization (WHO), hearing loss (HL) is one of the six key contributors to worldwide disease rates. It is becoming a critical issue in society, not just affecting the aging population, but also negatively impacting young people who are spending more of their spare time performing activities that expose them to excessive noise levels. In this research, we intend to design a filter as a signal processing system in a hearing aid (HA). MATLAB is used to model the digital filter structure, while Simulink is used to capture the entire design. This study examines current critical concerns in hearing aid research from the perspectives of a variety of disciplines. The study proposes a filter and signal processor model based on hearing aid experience, but first, it provides an audiogram for numerous examples to determine if the suggested model would suit or not. The work thus provides an effective compensation of missed high-frequency sounds response in patient hearing by the digital signal processor.
\end{abstract}

Keywords: Hearing Aid, Simulink, Hearing Filter.

\section{Introduction}

The main components of a human ear are the inner, middle, and outer ear, as well as the central nervous system that contain hair cells, and neurons, all playing a significant role to convert the surrounding sound into something the human brain can understand. When generating a sound, the resultant acoustic wave captured by the outer ear is converted into vibrations by the small bones in the middle ear. Then the vibrations proceed to the inner ear, where they pass through the cochlea, which is filled with fluid. The fluid displaces different regions along the basilar membrane of the cochlea. The acoustic wave's frequency information is incorporated in displacements along the basilar membrane ${ }^{[1]}$.

The membrane displaces maximum at different points depending on the frequency. The membrane is moved towards its apex when low frequencies are used and is stimulated at its base when high frequencies are used. The amplitude of the membrane's movement at any given position is proportional to the amplitude of the frequency that aroused it. The basilar membrane is moved at several locations when a sound is made up of numerous frequencies ${ }^{[2]}$. The cochlea splits complicated sounds into frequency components in this way hair cells are linked to each area of the basilar membrane, which bends proportionately to the membrane's displacement.
The bending generates an electrochemical response, which activates neurons to send sound data to the brain via the central nervous system.

Hearing loss (HL) is a serious health problem that affects a large population also, can be caused by a variety of factors ${ }^{[3]}$. Hearing impairments may be encountered with an anomaly in the audiogram due to most auditory diseases resulting in a reduction

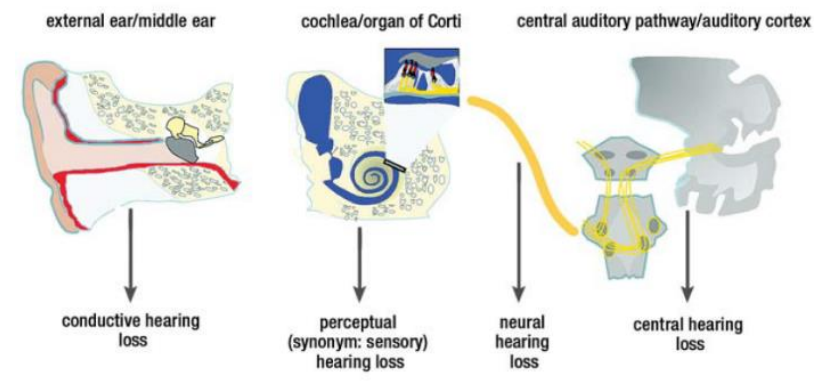

Figure 1: Topographic functional classification of HL according to the level of the lesion in the organs of hearing [1]

in hearing sensitivity ${ }^{[4]}$. With some surgical or pharmacologic procedures, complete hearing restoration is feasible in a minority of patients.

Other surgical treatments can provide partial functional hearing restoration, while biological and pharmacological therapies hold the possibility of hearing restoration in the future. These hearing

${ }^{*}$ Corresponding author. Tel.: +970504756160

E-mail: 100052989@ku.ac.ae

(C) 2021 International Association for Sharing Knowledge and Sustainability

DOI: $10.5383 /$ ijtee.17.02.005 
restoration procedures, however, only apply to a limited percentage of the hearing-impaired population ${ }^{[5]}$.

The basic topographic and functional differences between conductive, sensorineural, and central hearing loss are based on the severity of HL (as determined by pure-tone audiometry) and the main clinical categories (Table 1$)^{[6]}$. Other categorization approaches include age, temporal history, severity, and the pattern of fluctuation of the auditory threshold as a function of frequency on audiograms.

Hearing aids are extremely complicated electroacoustic devices that must operate in hostile surroundings, both physically and acoustically, with various intrinsic limits, such as restricted power supply, the necessity to be tiny, and the microphone's closeness to the receptacle ${ }^{[7]}$

Unsurprisingly that conceiving, designing, producing, testing, distributing, fitting, modifying, and assessing hearing aids require a very large number of professionals from a variety of separate disciplines ${ }^{[8]}$. The multidisciplinary nature of hearing aid research is one of the most difficult aspects of the field. Effective research, on the other hand, is required for high-impact studies that result in significant therapeutic advancements and improved patient outcomes.

Table 1: The WHO classification of the severity of HL, with general clinical recommendations ${ }^{[1]}$

\begin{tabular}{|c|c|c|c|}
\hline Grades of HL & $\begin{array}{l}\text { Mean } \mathrm{HL} \\
\text { in pure- } \\
\text { tone } \\
\text { audiogram }\end{array}$ & $\begin{array}{l}\text { Clinical } \\
\text { findings }\end{array}$ & Recommendations \\
\hline 0- NO Loss & $\begin{array}{l}25 \mathrm{~dB} \text { or } \\
\text { better }\end{array}$ & $\begin{array}{l}\text { No or very } \\
\text { slight hearing } \\
\text { Problems. } \\
\text { Able to hear } \\
\text { whispers. }\end{array}$ & $\begin{array}{l}\text { Counseling, follow-up examination; if } \\
\text { conductive } \\
\text { HL is present, evaluate indication } \\
\text { for surgery }\end{array}$ \\
\hline 1-Slight Loss & $26-40 \mathrm{~dB}$ & $\begin{array}{l}\text { Able to hear } \\
\text { and repeat } \\
\text { words spoken } \\
\text { in normal } \\
\text { voice at 1 } \\
\text { meter. }\end{array}$ & $\begin{array}{l}\text { Counseling, hearing aids may be } \\
\text { advisable; } \\
\text { if conductive HL or combined } \mathrm{HL} \text { is } \\
\text { present, surgical treatment } \\
\text { may be indicated }\end{array}$ \\
\hline $\begin{array}{l}\text { 2-Moderate } \\
\text { Loss }\end{array}$ & $41-60 \mathrm{~dB}$ & $\begin{array}{l}\text { Able to hear } \\
\text { and repeat } \\
\text { words spoken } \\
\text { in raised voice } \\
\text { at } 1 \text { meter }\end{array}$ & $\begin{array}{l}\text { HAs recommended; if conductive HL or } \\
\text { combined HL is present, surgical } \\
\text { treatment may be indicated }\end{array}$ \\
\hline 3 - Severe Loss & $61-80 \mathrm{~dB}$ & $\begin{array}{l}\text { Able to hear } \\
\text { and repeat } \\
\text { words spoken } \\
\text { shouted into } \\
\text { better ear. }\end{array}$ & $\begin{array}{l}\text { HAs needed; if an external HA is not } \\
\text { possible, consider an implanted HA or } \\
\text { cochlear implant; lip-reading and } \\
\text { signing for supportive treatment }\end{array}$ \\
\hline $\begin{array}{l}\text { 4-Major Loss } \\
\text { (including } \\
\text { deafness) }\end{array}$ & $\begin{array}{l}81 \text { dB or } \\
\text { higher }\end{array}$ & $\begin{array}{l}\text { Unable to hear } \\
\text { and understand } \\
\text { even a } \\
\text { shouted voice. }\end{array}$ & $\begin{array}{l}\text { Failure of a HA trial is now usually } \\
\text { considered an indication for a cochlear } \\
\text { or brainstem implant; lip-reading and } \\
\text { signing } \\
\text { can be taught in addition }\end{array}$ \\
\hline
\end{tabular}

In the future generations, over 1 billion individuals will suffer from age-related, chronic sensorineural HL, for which acoustic HAs will be the only option. The examination of current work done in HA has revealed a shortage in adaptability, and lack of accuracy regarding the truth that the main objective is to enhance the overall hearing experience not the individual case itself. The proposed method can self-learn the features from the audiogram test for each patient which support the filter with the needed compensation for the failure in hearing sense. Simulation results prove that the proposed system is befitting for multi cases even with noise cancellation.

This study examines current critical concerns in hearing aid research from the perspectives of a variety of disciplines. The study proposes a filter and signal processor model based on hearing aid experience, but first, it provides an audiogram for numerous examples to determine if the suggested model would suit or not.

\section{Hearing Aids: Overview}

Depending on the HL types and severity, HAs may be useful in treating presbycusis. Some hearing aid models and features are more suited for a particular type of hearing loss than others, Classic behind-the-ear, in-canal, completely-in-canal, and openfit HAs now come in a range of forms and sizes. Some microphones may be pointed in various directions. There are two types of electronic HAs: digital and analog.

Analog hearing aids use a microphone to record sound waves, convert them to electrical impulses, amplify them, and transmit them to the tympanic membrane via the ear canal ${ }^{[9]}$. Different parameters for different hearing conditions can be modified. Analog HAs been less costly than digital HAs and have a more linear frequency amplification approach. While you can obtain a lot of extra functions with digital hearing aids that you can't get with analog hearing aids, you can't get them with analog hearing aids. HAs that are fully digital can be programmed with a range of programs that the user may choose from or that function automatically and adaptively ${ }^{[10]}$. These algorithms eliminate acoustic feedback, minimize background noise, detect and alter different listening settings, regulate additional components like multiple microphones to increase spatial hearing, transpose frequencies (transfer high frequencies that a wearer may not hear to lower frequency areas where hearing may be improved), and do a variety of other tasks ${ }^{[11]}$.

The following components are found in most current hearing aids, as shown in Fig. [12] $^{[1}$

1. A microphone to take up external sound.

2. A preamplifier for each microphone, with a low-pass filter to restrict the maximum frequency that is present, to improve the electrical signal amplitude. (The cutoff frequency is usually $9 \mathrm{kHz}$ or below.)

3. For each amplified microphone signal, an analog-todigital converter. This transforms a constantly fluctuating voltage into a series of integers that reflect the voltage at discrete, regularly spaced points in time. The sampling rate is defined as the number of samples taken every second.

4. A tiny computer that performs functions such as frequency-dependent amplification, amplitude compression and limiting, noise reduction, acoustic feedback suppression, and directional processing called digital signal processor (DSP).

5. A device that acts as a receiver that turns the output of a signal processor into sound. A digital-to-analog converter is occasionally used for this, but in many hearing aids, the receiver translates the processor's digital output directly into sound.

6. A battery to power the receiver and circuits.

7. A housing for the majority of the above-mentioned components and is tailored to fit the external ear and ear canal.

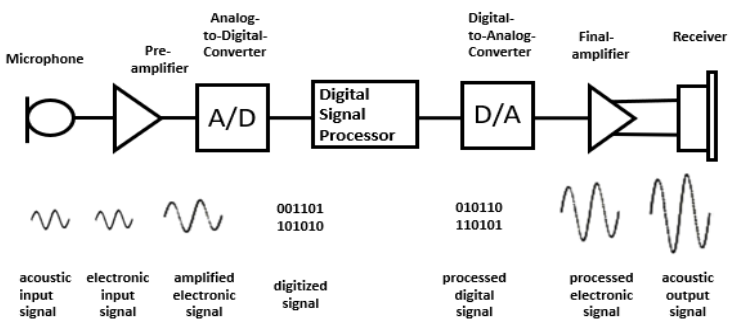

Figure 2:Hearing Aid Main Components [11] 
Signal Processing contributes to the solution of the challenge of converting acoustic waves to electrical impulses. DSP in HAs divides an acoustic wave input into multi-component frequencies, which are then each delivered to an electrode that acts like nerves, that mimics the cochlea basilar membrane ${ }^{[13]}$ High-frequency (high-pitched) signals are transmitted by electrodes at the base, whereas low-frequency (low-pitched) signals are transmitted by electrodes at the top. Nerve fibers around the proposed electrodes are accelerated and then sent that information to the brain as electrical form. Furthermore, loud noises create high-amplitude electrical pulses that stimulate more nerve fibers, whereas quiet sounds stimulate fewer nerve fibers ${ }^{[14]}$. Information on the component amplitude and frequencies that make up a sound can be sent to the patient's brain in this way.

\section{Model development}

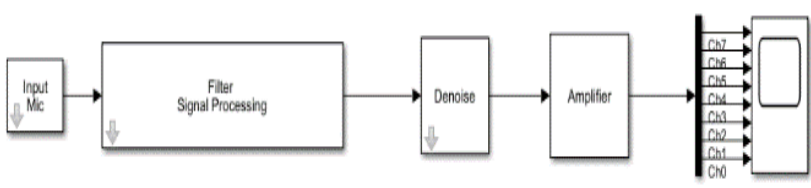

Figure 4: Model Block Diagram

This model illustrates some of the decisions taken while constructing speech filter processors with the MATLAB Simulink DSP and Audio System Toolbox ${ }^{\mathrm{TM}}$. The advantages of utilizing a cascaded multistage filter rather than a single rate, parallel, and second-order-section Infinite impulse response (IIR) filter bank are demonstrated in detail.

As illustrated in Fig 3 the microphone takes up sound through the electrical pulses that are created, where the block in the model illustrates a speech processor. From Channel 0, which broadcasts the lowest frequency $(0-0.4 \mathrm{kHz})$, to Channel 7 , which transmits the highest frequency $(4.8-10.0 \mathrm{kHz})$, as illustrated in Table 2.

The Filter Signal Processing component is responsible for decomposing the incoming speech signal into eight overlapping sub-bands. The sub-bands are positioned so that the lowerfrequency bands are narrower to acquire as much resolution as possible where the most information is present. The four lowfrequency bands are evenly spaced in this model, whereas each of the other last 4 high-frequency bands has double the bandwidth of the first 4 lower-frequency bands.

Table 2:Model 8 Channels Frequencies

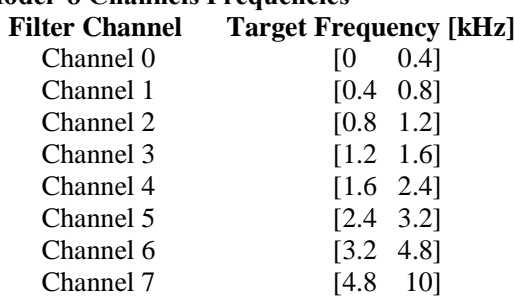

The proposed filter implements $6^{\text {th }}$ stage IIR filters as $2^{\text {nd }}$ sections (SOS). To achieve optimal scaling benefits, the DSP System Toolbox ${ }^{\mathrm{TM}}$ scale function is employed. At the input signal rate, the eight filters run in parallel. The concepts of a method that combines downsampling and filtering at each filter step guided the creation of this filter. Each sub-total band's filter response is calculated by cascading its components.

\section{Result and Discussion}

The first step in implementing this model was to take more hearing tests using MATLAB-based audiogram that create frequency sweep up to $16 \mathrm{kHz}$ within amplitude range from 0 $25 \mathrm{~dB}$, which simulate the normal human range of hearing. The decision will be made as a compensator to the DSP filter to target the missing frequencies according to the difference between the patient result and the normal range. As illustrated in Fig 4 normal hearing range is around $25 \mathrm{~dB}$ for low and high frequencies but the patients have drop response in three main frequencies $(6,8,12 \mathrm{kHz})$.

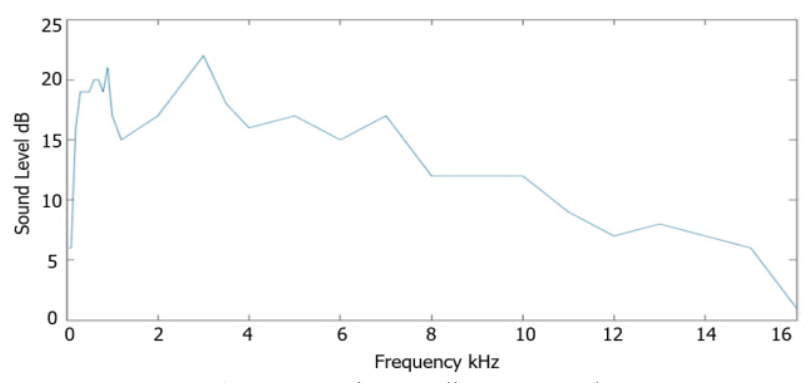

Figure 5: Patient Audiogram Result

The suggested model depicts the construction of a HA filter that could be implanted in a patient inner ear to restore partial hearing. Sound is converted to electrical pulses through signal processing. To offer partial hearing, the modulated pulses can go around the damaged regions of the patient's ear then be transferred to the brain. As seen in Fig 5 after targeting three main frequencies in the DSP how it modulates and compensates the missing frequencies to stimulate the healthy ear response.
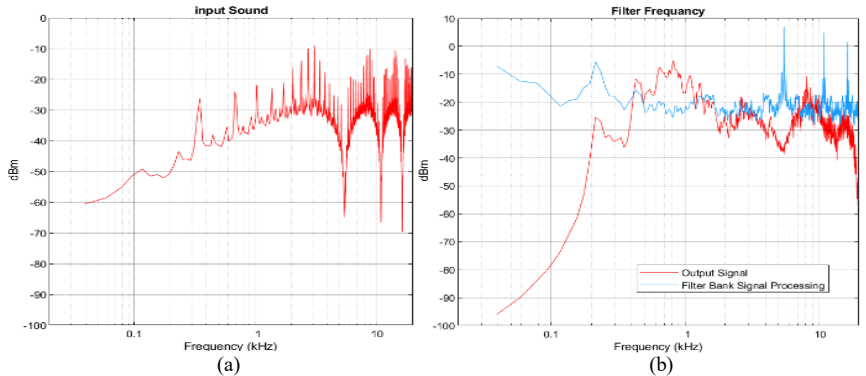

Figure 3: The Digital Signal Processor a) Input Signal and b) Output Signal

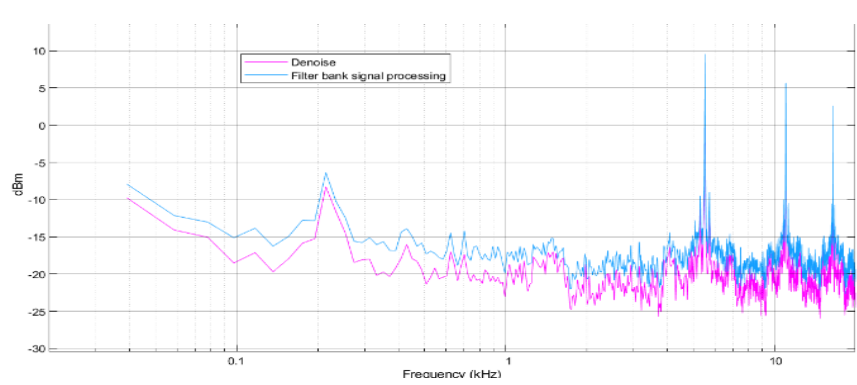

Figure 6: Denoise Effect on the DSP Filter

Also, Fig 6 illustrates the 8 channel frequencies and magnitude distributed along 0 to $10 \mathrm{kHz}$, which shows that the loss in higher frequencies. Furthermore, Fig 6 briefly shows the denoise block of the DSP filter process. 

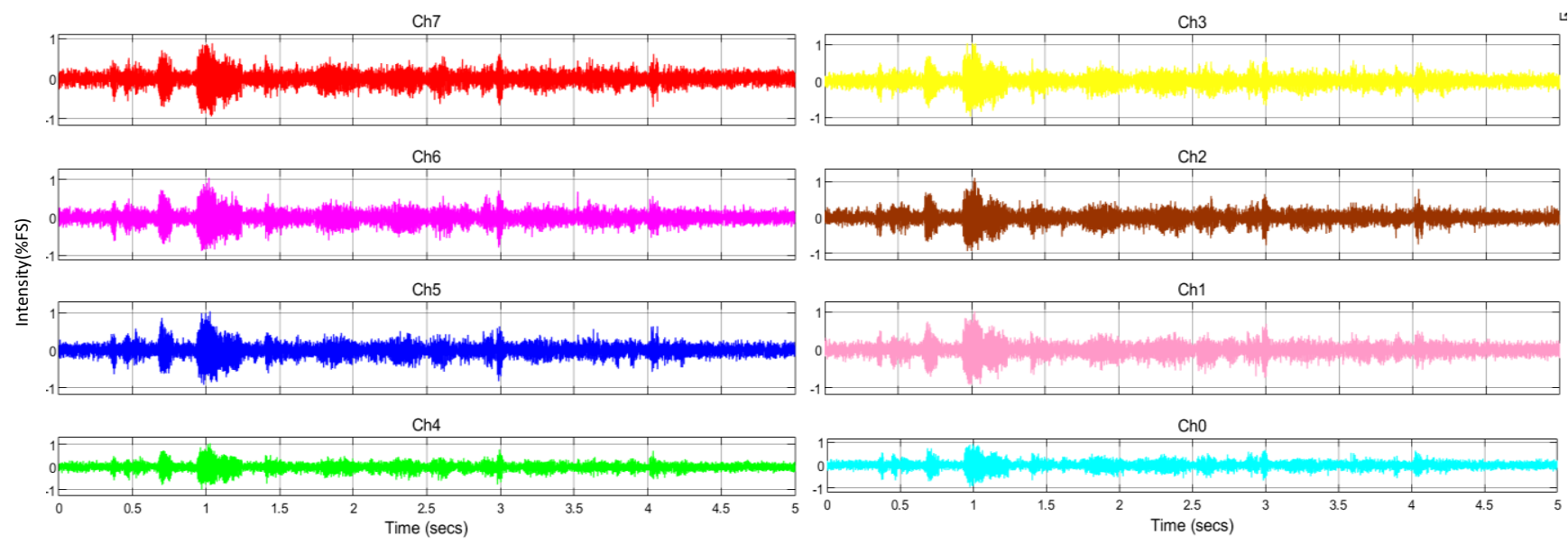

(a)
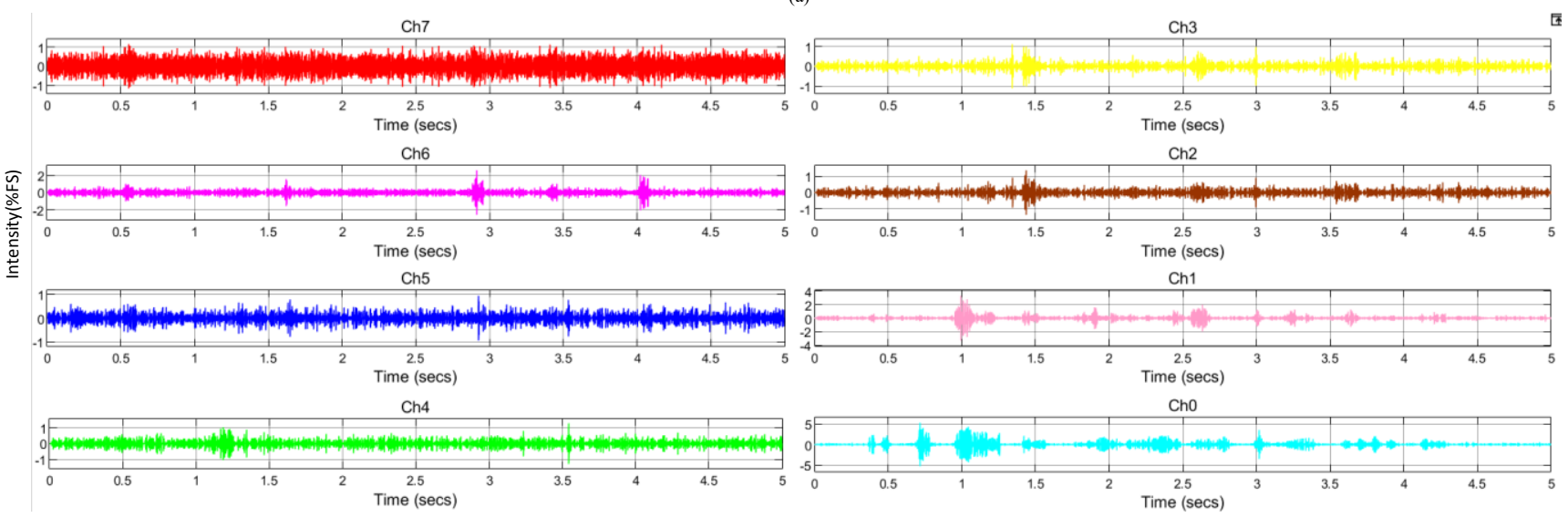

(b)

Figure 7: The DSP a) Sound Input b) Sound Output

While Fig 7 illuminated sound intensity Vs time for the input sound and the output signal as process it in DSP 8 channels.

\section{Conclusion}

The HAs filter has been successful in recovering partial hearing loss in patients. Many people with HAs can converse and understand speech without the use of lip-reading, and some can even chat on the phone. Much of the success of HAs may be attributed to the development of DSP techniques over time. While this progress is encouraging, there is still much to learn about the auditory nerve electrical stimulation, as well as many unanswered concerns. In the future, investigations can be continued to understand the strengths and limits of current signal-processing techniques in filter design research. The results of these studies might lead to the development of DSP systems that can send more information to the brain, develop noise-reduction algorithms to assist hearing-impaired patients to converse more effectively in loud surroundings. The development of signal-processing algorithms that are resilient in the face of conflicting noise would be desired and determination

\section{References}

${ }^{1}$ Loizou, P. C. (1998). Mimicking the human ear. IEEE signal processing magazine, 15(5), 101-130.

2 . B. Wilson, "Signal processing," in Cochlear Implants: Audiological Foundations of the elements that lead to patient performance variability. Knowing these parameters may aid in the development of patient-specific signal processing algorithms. Patients will subsequently be fitted with signal processors that are considerably more suited to them.

\section{Nomenclature}

$\begin{array}{ll}\text { HL } & \text { Hearing Loss } \\ \text { HA } & \text { Hearing Aid } \\ \text { DSP } & \text { Digital Signal Processor } \\ \text { IIR } & \text { Infinite impulse response }\end{array}$

(R. Tyler, ed.), pp. 35-86, Singular Publishing Group, Inc, 1993 ${ }^{3}$ Moore, B. C., \& Popelka, G. R. (2016). Introduction to hearing aids. In Hearing Aids (pp. 1-19). Springer, Cham. 
${ }^{4}$ Zahnert, T. (2011). The differential diagnosis of hearing loss. Deutsches ärzteblatt international, 108(25), 433.

${ }^{5}$ Mallik, S., Chowdhury, D., \& Chttopadhyay, M. (2019). Development and performance analysis of a low-cost MEMS microphone-based hearing aid with three different audio amplifiers. Innovations in Systems and Software Engineering, 15(1), 17-25

${ }^{6}$ Sprinzl, G. M., \& Riechelmann, H. (2010). Current trends in treating hearing loss in elderly people: a review of the technology and treatment options-a mini-review. Gerontology, 56(3), 351-358.

${ }^{7}$ Ali, W. R., \& Prasad, M. (2020). Piezoelectric MEMS based acoustic sensors: A review. Sensors and Actuators A: Physical, 301, 111756.

8 Levitt, H. (2001). Noise reduction in hearing aids: A review. Journal of rehabilitation research and development, 38(1), 111-122.

9 James, W. (2000). Development of the ear and hearing. Journal of perinatology, 20(8).
${ }^{10}$ Devis, T., \& Manuel, M. (2018, August). Multirate and filterbank approaches in digital hearing aid design: A review. In IOP Conference Series: Materials Science and Engineering (Vol. 396, No. 1, p. 012036). IOP Publishing.

${ }^{11}$ Håkansson, B., Tjellström, A., Rosenhall, U., \& Carlsson, P. (1985). The bone-anchored hearing aid: principal design and a psychoacoustical evaluation. Acta oto-laryngologica, 100(3-4), 229-239.

${ }^{12}$ Popelka, G. R., Moore, B. C., Fay, R. R., \& Popper, A. N. (Eds.). (2016). Hearing aids. Springer International Publishing. ${ }^{13}$ Vicen-Bueno, R., Gil-Pita, R., Utrilla-Manso, M., \& AlvarezPerez, L. (2007, October). A hearing aid simulator to test adaptive signal processing algorithms. In 2007 IEEE International Symposium on Intelligent Signal Processing (pp. 1-6). IEEE.

14 VOLANDRI, G. (2012). Development of Mathematical Models of a Human Virtual Ear. 